\title{
Experiência de uso do Whatsapp como Ambiente Virtual de Aprendizagem em um curso a distância
}

\author{
Estêvão Domingos Soares de Oliveira ${ }^{1}$, Hercilio de Medeiros Sousa ${ }^{2}$, Eudisley \\ Gomes dos Anjos ${ }^{3}$, Jose Jorge Lima Dias Junior ${ }^{4}$, Jan Edson Rodrigues Leite ${ }^{5}$, \\ Felipe Soares de Oliveira ${ }^{6}$ \\ ${ }^{1}$ Universidade Federal da Paraíba/PPGI/UFPB Virtual \\ ${ }^{2}$ Universidade Federal da Paraíba/PPGI/UFPB Virtual \\ ${ }^{3}$ Universidade Federal da Paraíba/Centro de Informática \\ ${ }^{4}$ Universidade Federal da Paraíba/Centro de Ciências Aplicadas e Educação \\ ${ }^{5}$ Universidade Federal da Paraíba/Centro de Ciências Humanas, Letras e Artes \\ ${ }^{6}$ Universidade Federal de Pernambuco/Cin \\ estevaodso@gmail.com, \{hercilio,jan\}@virtual.ufpb.br, \\ eudisley@ci.ufpb.br, jorge@dce.ufpb.br, felipesoaresdo@gmail.com
}

\begin{abstract}
The increasing use of mobile technologies has led distance education programs to adopt several new models of learning. Herewith, Mobile Learning has been used inside and outside the classroom as a powerful teaching tool. In this paper, we present an experience report on applying M-Learning to a distance teachers training course at college level carried out at the UFPB Virtual. The results demonstrate the benefits this type of learning can bring and also indicates the weaknesses of its present format.
\end{abstract}

Resumo. O crescente uso das tecnologias móveis tem levado a educação a distância a adotar novas modalidades de aprendizagem. Em decorrência disso, o Mobile Learning tem sido utilizado dentro e fora da sala de aula como uma poderosa ferramenta de ensino. Neste trabalho, apresentamos um relato de experiência da aplicação de um curso a distância, a partir da perspectiva do M-Learning, para professores e tutores da UFPB Virtual onde foi utilizado o aplicativo para dispositivos móveis Whatsapp. Os resultados demonstram o poder que essa modalidade de aprendizagem pode ter $e$ também indica os pontos fracos da mesma.

\section{Introdução}

Hoje, aproximadamente 43 milhões de brasileiros acessam a Internet por dispositivos móveis (Instituto Datafolha ${ }^{1}$ ). Estima-se que mais da metade desse número seja de indivíduos com idade entre 12 e $34 \operatorname{anos}^{2}$, o que evidencia que boa parte destes usuários estão inseridos no ensino básico, secundário ou superior. Diante disso, uma nova possibilidade de ensino e aprendizagem surge que, segundo Laouris \& Eteokleous (2005), foi denominada de aprendizagem móvel ou M-Learning (Mobile Learning).

De forma geral, o M-Learning é uma modalidade de ensino onde os dispositivos móveis são utilizados dentro e fora de sala de aula para auxiliar o processo de

\footnotetext{
${ }_{1}$ http://datafolha.folha.uol.com.br/mercado/2014/01/1400618-43-milhoes-de-brasileiros-acessam-internet-por-dispositivosmoveis.shtml

2 http://gestaodecomunidades.com/infograficos/infografico-perfil-usuarios-dispositivos-moveis-brasil
} 
aprendizagem. Deste modo, os alunos e professores podem usufruir de materiais instrucionais de vários formatos, em qualquer hora e lugar, bem como dos inúmeros recursos tecnológicos oferecidos por essas tecnologias.

Algumas pesquisas têm demonstrado que, apesar do crescimento constante, a aprendizagem móvel ainda não é utilizada de forma significativa por parte dos educadores, tal como mencionado em Crescente, M. \& Lee, D. (2011).

Diante dessa realidade, este trabalho tem como objetivo apresentar uma possibilidade de uso de dispositivos móveis na educação a distância, propiciando aos professores novas experiências replicáveis em diversos contextos. Para isso, descreveremos um relato de experiência de um curso ministrado através do aplicativo Whatsapp e que teve como público-alvo professores e tutores da UFPB Virtual (Unidade de Educação a Distância da Universidade Federal da Paraíba). O trabalho está dividido como se segue. Na sessão 2, aborda-se o referencial teórico. A sessão 3 mostra a metodologia que adotou-se para que o trabalho fosse possível. As fases em que o curso foi dividido é descrito na sessão 4 e, na sessão 5 , discutiu-se os pontos mais relevantes do presente trabalho e por fim, na sessão 6 , conclui-se o relato com exposição dos trabalhos futuros.

\section{Referencial Teórico}

$\mathrm{Na}$ educação a distância e mais especificamente na aprendizagem móvel, diversas tecnologias existentes podem estar envolvidas no processo de aprendizagem. Nesta sessão, descrevem-se as que foram utilizadas para esse trabalho, destacando-se suas vantagens e desvantagens.

\subsection{Mobile Learning}

Derivado do E-Learning, o M-Learning é entendido como sendo a junção dos conceitos de mobilidade e aprendizagem. Neste contexto, Segundo Saccol, Schlemmer e Barbosa (2011),

"processos de aprendizagem apoiados pelo uso de tecnologias da informação ou comunicação móveis e sem fio, cuja característica fundamental é a mobilidade dos aprendizes, que podem estar distante uns dos outros e também de espaços formais de educação, tais com salas de aula, salas de formação, capacitação e treinamento ou local de trabalho" (p. 23).

O paradigma $M$-Learning se utiliza das tecnologias de redes sem fio; serviços de correio de voz; e-mail; transmissão de sons, fotos e vídeos; serviços de mensagens curtas (SMS); multimídia message service (MMS), etc. Diante de tantos recursos, algumas vantagens podem ser destacadas ao se fazer a aplicação prática do conceito de M-Learning: Mobilidade (a qualquer momento e lugar); maior interatividade e colaboração entre usuários e acessos rápidos a conteúdos importantes.

No tópico seguinte, se dará uma visão geral do Whatsapp - aplicativo escolhido para o desenvolvimento desta proposta.

\subsection{Whatsapp}

WhatsApp é um aplicativo multiplataforma que permite trocar mensagens pelo celular gratuitamente, além disso, seus usuários podem criar grupos de até 50 participantes; enviar mensagens ilimitadas com imagens, vídeos e áudio; compartilhar localização; fazer backup do conteúdo postado nos grupos, etc. Acessando o link 
http://www.whatsapp.com vê-se vários detalhes técnicos do aplicativo. Na próxima sessão, descreveremos a metodologia utilizada.

\section{Metodologia}

O presente estudo constitui-se do resultado de um curso a distância que utilizou como Ambiente Virtual de Aprendizagem o aplicativo Whatsapp e teve como público alvo, como mencionado anteriormente, professores e tutores que atuam na UFPB Virtual. $\mathrm{O}$ curso foi planejado para 48 participantes e mais 2 mediadores estes últimos atuaram sugerindo discussões, tirando dúvidas e auxiliando no uso do aplicativo.

A observação foi realizada a partir das discussões levantadas pelos mediadores no decorrer de cinco semanas. Para cada semana, um grupo foi criado para que os assuntos discutidos fossem bem delimitados. A ideia foi que cada grupo funcionasse como um fórum de discussão, onde há a possibilidade de se compartilhar textos, mensagens de áudio, vídeo, links, etc.

Para a semana 1, propôs-se um período de ambientação no Whatsapp e à proposta do curso. Na semana 2, o focou-se no assunto Aprendizagem Móvel. Nas semanas 3 e 4, abordou-se Games e Gamificação e Games aplicados à Educação, respectivamente e, na última semana do curso, 5 , deu-se a apresentação dos trabalhos finais.

Criou-se ainda mais dois grupos: "Tira Dúvidas", onde os participantes poderiam, a qualquer momento, tirar dúvidas de ordem técnica e sobre o curso de modo geral, e "Social", em que qualquer conteúdo, relativo ou não ao curso, poderia ser compartilhado com os demais. Na Semana 5, um formulário online foi enviado aos participantes para que os mesmos respondessem e, com esse feedback, um relatório sobre as dificuldades dos participantes fosse construído e traduzido em gráficos abordados a seguir.

\section{O Curso}

Devido à ampla utilização de dispositivos móveis atualmente, decidiu-se pesquisar aplicativos populares no ambiente móvel e verificar aquele que possuía recursos suficientes para prover um curso a distância. Selecionou-se, assim, o aplicativo Whatsapp. Definiu-se, em sequência, o público alvo, que, como já dito, foi composto por professores e tutores da UFPB Virtual. Depois, escolheu-se o tema Gamificação, baseado nas previsões do Horizon Report Higher Education Edition (2012). Adotou-se o sistema operacional Android como padrão para o curso, tendo em vista sua popularidade e, assim, os aplicativos e jogos utilizados durante o curso seriam melhor direcionados pelos mediadores. Concluiu-se esta primeira parte do planejamento intitulando o curso de: M-Learning através do Whatsapp: Games e Gamificação em EaD.

Posteriormente, fez-se a seleção do material instrucional que seria utilizado no curso. Como o aplicativo possui uma limitação de envio de arquivos de tipo texto (txt, doc, docx, pdf, etc.) entre usuários, tiraram-se fotos do material impresso e, para melhor organização, cada imagem era numerada com as seguintes informações: Semana, texto e página. Além das fotos de textos, produziram-se materiais gráficos com as principais informações do curso. Os recursos de gravação de áudio e vídeo também foram utilizados para repassar os pontos norteadores do curso. 
Criou-se 6 (seis) grupos no Whatsapp onde cada um deles possuía uma função específica para melhor gerenciamento dos dados produzidos. A capacitação iniciou-se com uma semana de ambientação que ocorreu no período de 24/03/2014 a 30/03/2014. Neste espaço, disponibilizou-se 3 imagens: o cronograma, as regras para condução e boas práticas para um melhor aproveitamento do curso.

Após a semana de ambientação, no período de 31/03/2014 a 06/04/2014, iniciou-se a utilização do grupo semana 1, onde tratou-se das definições de M-Learning, U-Learning e E-Learning. No grupo semana 2, que ocorreu de 07/04/2014 a 13/04/2014, tratou-se da definição dos conceitos de Games e Gamificação. Essa semana a discussão foi mais intensa e participativa que a anterior, chegando a gerar certa dificuldade para o acompanhamento do grupo.

No período de 14/04/2014 a 20/04/2014, ocorreu o grupo semana 3, onde foram apresentados pelos ministrantes do curso exemplos de jogos que contemplavam a ideia de Gamificação. Na última semana do curso, que ocorreu no grupo semana 4 e no período de 21/04/2014 a 27/04/2014, disponibilizou-se apenas um vídeo com informações sobre o processo avaliativo da capacitação. Nele constava um exemplo de jogo que apresentava princípios da Gamificação e solicitou-se aos cursistas que apresentassem jogos com tais princípios, da mesma forma que fora feito na semana anterior e no vídeo norteador desta semana.

\subsection{Avaliação do Curso de Formação pelos Cursistas}

No decorrer do grupo semana 4, disponibilizou-se um questionário opcional de pesquisa para levantamento de dados acerca do grau de satisfação dos cursistas quanto a esta inovação na forma de ensino mediada por um aplicativo de celular. Nesta pesquisa, apenas os 26 cursistas que enviaram suas atividades avaliativas finais responderam.

\section{Discussão}

A literatura tem demonstrado que ainda há uma carência por parte das instituições para enfrentar mudanças sociais (Naismith et al., 2004). Entretanto, muitos estudos tratam da aprendizagem apoiada por tecnologias móveis como as pesquisas referidas em Kukulska-Hulme \& Traxler (2005).

De um modo geral, os estudantes têm uma receptividade positiva em relação ao uso da aprendizagem móvel (Guy, 2009). De fato, os participantes do curso demonstraram grande aceitabilidade com esta nova proposta de uso.

Vavoula (2005) destaca que a aprendizagem não deve estar desconectada das atividades cotidianas, mas sim ligada aos processos mais comuns do dia-a-dia, como conversar, ler, fazer compras, enfim, entretenimento de modo geral.

Rajasingham (2009) afirma que os modelos educacionais que rompem com os métodos convencionais de ensino estão se tornando cada vez mais plausíveis com a ajuda da crescente evolução da tecnologia da informação. Os resultados deste estudo corroboram com o autor, visto que as possibilidades que a aprendizagem móvel suporta estão facilitando a vida dos alunos, uma vez que podem acessar suas bibliotecas digitais a qualquer hora e lugar, contribuindo assim para o sucesso do processo de ensinoaprendizagem.

\section{Conclusão}


O presente relato demonstrou a utilização do Whatsapp como um ambiente virtual de aprendizagem para um curso de capacitação de professores e tutores. Tal proposta é vista como uma inovação, já que na amplitude dos estudos relacionados às tecnologias no processo de ensino-aprendizagem, há uma forte tendência a expansão do uso do $M$ Learning como apoio ao ensino presencial.

Para a eficaz utilização deste aplicativo, é necessário planejamento e organização, já que, sem estes, devido a rápida e dinâmica troca de mensagens, a condução das interações entre os participantes pode se tornar problemática, interferindo negativamente nos resultados esperados.

Diante do exposto e dos resultados obtidos, visualiza-se o aplicativo Whatsapp como uma alternativa eficaz para o ensino-aprendizagem, já que implementou-se motivação e satisfação aos cursistas, aumentando as relações pessoais entre os membros do grupo e a sensação de comunidade e colaboração do grupo. Tudo isso gera um trabalho com dinamismo, o que facilita o aprendizado em capacitações mediadas a distância.

Como trabalhos futuros, pretende-se replicar este modelo abordando outros assuntos, de diferentes áreas, abrangendo outros públicos-alvo, como, por exemplo, alunos do ensino médio.

\section{Referências}

CRESCENTE, Mary Louise; LEE, Doris. Critical issues of M-Learning: design models, adoption processes, and future trends. Journal Of The Chinese Institute Of Industrial Engineers, v. 2, n. 28, p.111-123, jan. 2011.

COSTA, R. Tele-Experimentação Móvel (Mobile Remote Experimentation) Considerações sobre uma área emergente no ensino à distância. 2005. Disponível em:

<http://ave.dee.isep.ipp.pt/ rjc/Docs/2005/NewsletterISEP2005/NewsLetterISEP.pdf $>$. Acesso em: 15 jun. 2014.

GUY (org.), The Evolution of Mobile Teaching and Learning. Santa Rosa, CA: Informing Science Press, 2009.

HORIZON REPORT: 2012 HIGHER EDUCATION EDITION. Austin, Texas: The New Media Consortium, 2012.

LAOURIS, Y., \& ETEOKLEOUS, N. (2005). We need an educational relevant definition of mobile learning. Retrieved May 15, 2010.

NAISMITH L., LONSDALE P., VAVOULA G., and SHARPLES, M. Literature Review in Mobile Technologies and Learning, Report 11, Future lab Series, 2004.

RAJASINGHAM, L.. Breaking boundaries: Quality eLearning for global knowledge society. International Journal of Emerging Technologies in Learning, 2009.

SACCOL, Amarolinda; SCHLEMMER, Eliane; BARBOSA, Jorge. M-Learning e $U$ Learning: novas perspectivas de aprendizagem móvel e ubiqua. São Paulo: Pearson Prentice Hall, 2011.

VAVOULA, G. N. D4.4: A Study of Mobile Learning Practices: Internal report of MOBIlearn Project, 2005. 